\title{
Lamination Core Losses in Motors With Nonsinusoidal Excitation With Particular Reference to PWM and SRM Excitation Waveforms
}

\author{
Tsakani Lotten Mthombeni, Student Member, IEEE, and Pragasen Pillay, Fellow, IEEE
}

\begin{abstract}
The effects of varying the modulation index and the switching frequency on steel lamination core losses when excited with pulse width modulated waveforms are first investigated. A switched reluctance motor flux model is also developed and flux waveforms for different parts of the machine are synthesized. Using these flux waveforms, the paper presents the loss trend inside a switched reluctance machine, showing the core loss variation of the machine. The rotor was found to incur higher losses than any other part inside the switched reluctance motor. The paper further identifies the flux density harmonics that contribute to higher core losses in the rotor. Using the Fourier series, an attempt to predict core losses under switched reluctance motor flux density waveforms is done and the predicted results are compared with measurements. An Epstein frame was used for direct core loss measurements on 0.0140 in. [0.36 mm] commercial electrical steel; the methods and test bench used, along with test results are detailed in the paper.
\end{abstract}

Index Terms-Core loss, Epstein square, harmonics, pulsewidth modulation, switched reluctance motor.

\section{INTRODUCTION}

C ORE loss data is one of the major characteristics used to grade electrical steel used for electrical motor designs. In electrical machines, core loss amounts to $20-25 \%$ of the total losses [1], this being valid under sinusoidal supplies, for $50 \mathrm{~Hz}$ or $60 \mathrm{~Hz}$. When fed from an inverter, a motor experiences various frequencies higher than $50 / 60 \mathrm{~Hz}$ and the $50 / 60 \mathrm{~Hz}$ core loss data from steel manufacturers is not appropriate in determining the core losses accurately. Besides PWM supplies, nonsinusoidal excitation exists by design in some machines like the switched reluctance motors (SRM) [2], thus resulting in increased core losses.

In SRMs, torque is produced due to the nonsinusoidal nature of the flux patterns, as the poles tend to align. SRMs are becoming popular as part of a drive system and represent a real alternative to conventional drives in many applications, e.g. the automotive industry. This is mainly because of their rotor construction with no windings. In high-speed applications of SRMs,

Manuscript received November 26, 2003; revised October 27, 2004. This work was supported by the Electric Motor Education and Research Foundation (EMERF) Consortium under The Motor and Motion Association (SMMA). Paper no. TEC-00349-2003.

T. L. Mthombeni is with the Department of Electrical and Computer Engineering, Clarkson University, Potsdam, NY 13699-5722 USA (e-mail: mthomblt@clarkson.edu).

P. Pillay is with the Department of Electrical and Computer Engineering, Clarkson University, Potsdam, NY 13699-5720 USA, on leave from the University of Cape Town, Cape Town, South Africa (e-mail: pillayp@ clarkson.edu).

Digital Object Identifier 10.1109/TEC.2005.847947 core losses become a dominant component of the total losses. In order to develop an optimized SRM drive, a model for calculating the losses is important, the complexity of which is attributed to the nature of the flux waveforms, i.e., nonsinusoidal with different waveforms in different parts of the motor. The flux waveforms change with the motor design: number of stator and rotor poles, number of phases, operating conditions, conduction angle and mechanical speed. It therefore becomes necessary for motor designers to know, either by measurements or estimation, the core loss of the steel used to design motors.

A four-phase 8/6 SRM is investigated in this paper. Loss measurements on motor laminations using an Epstein frame were conducted. While it is true that the motor lamination core losses will be affected during the design process of the motor (through cutting, stamping etc), the loss trend presented here gives motor designers some insight into the core loss distribution inside the motor.

In [2], a core loss trend inside the SRM was presented using core loss measurements only. This paper advances that work in the following manner: Firstly, through core loss predictions and measurements the core loss trend inside the SRM is presented. Secondly, flux harmonics that contribute to the core losses are identified. Thirdly, core losses are predicted using the flux harmonics, which is an attempt to quantify the error involved when using the Fourier series to predict core losses. This paper uses the latest high frequency core loss data from steel manufacturers (which was not available to the public until recently [3]), to attempt to predict core losses under nonsinusoidal supplies. While the superposition principle may not necessarily hold under practical working conditions of a heavily saturated machine, the results presented here show what could be achieved using the recent data in [3]. The verification and understanding of PWM losses is important before testing standards are to be developed.

In [4], a test bench has been proposed for measuring core losses on magnetic samples under variable frequency supplies. This test bench is adopted here and extended to SRM core loss testing. Factors such as fringing effects, saturation and rotational losses were not studied in the work reported here.

Section II describes the test bench used to measure core losses under nonsinusoidal waveforms, followed by results and analysis of findings with PWM losses. Section III outlines a mathematical description of the SRM flux model adopted together with a harmonic analysis of the SRM flux waveforms. Section IV presents a comparison of the predicted loss trend and the actual measured loss results, for each part of the motor. Finally, Section V presents the conclusions. 


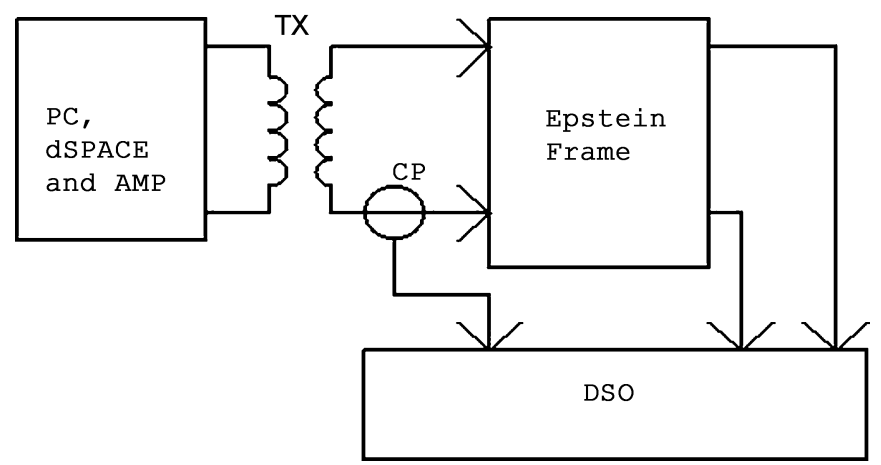

Fig. 1. Test bench used to measure core loss under nonsinusoidal excitations.

\section{PWM LOSS MEASUREMENT RESULTS AND ANALYSIS}

The test bench used to measure core losses under nonsinusoidal supplies is described below followed by core loss results when laminations are excited with PWM waveforms.

\section{A. Test Bench Description}

A schematic diagram of the test bench is shown in Fig. 1. The nonsinusoidal signals were generated in a computer (PC) using Matlab Simulink and through DSP based dSPACE software and hardware (with D/As). The generated waveforms are amplified by a high bandwidth linear amplifier (AMP $100 \mathrm{kHz}$ ) and used as a power source to excite the Epstein frame. A single-phase transformer (TX) was connected between the amplifier and the Epstein frame, to eliminate the dc component in the voltage waveforms [4]. A current probe (CP) and an isolated differential voltage probe were used to measure the exciting current and secondary voltage, respectively. A digital storage oscilloscope (DSO), Nicolet Integra 40 model was used to monitor and store exciting current, secondary voltage and their instantaneous product (power) for offline analysis.

In [4], fundamental work on measuring core losses under PWM supplies was done; this section verifies those results reported in [4]. Using the test bench in Fig. 1, the following PWM inverter parameters were varied to observe their influence on core losses:

- modulation index ( $m_{a}$, amplitude ratios of the control to the switching waveform);

- switching frequency $\left(f_{s}\right)$.

Using a sinusoidal PWM and unipolar switching, core losses were measured. A peak fundamental flux was used as a reference. Using the separation of loss principle, total core losses can be expressed as

$$
P_{\text {core }}=P_{h}+P_{e}+P_{e x}, \quad(\mathrm{~W} / \mathrm{kg})
$$

where

$$
\begin{aligned}
P_{h} & =K_{1} \int H d B, \quad(\mathrm{~W} / \mathrm{kg}) \\
P_{e} & =K_{2} \int\left|\frac{d B}{d t}\right|^{2} d t, \quad(\mathrm{~W} / \mathrm{kg}) \\
P_{e x} & =K_{3} \int\left|\frac{d B}{d t}\right|^{\frac{3}{2}} d t, \quad(\mathrm{~W} / \mathrm{kg})
\end{aligned}
$$

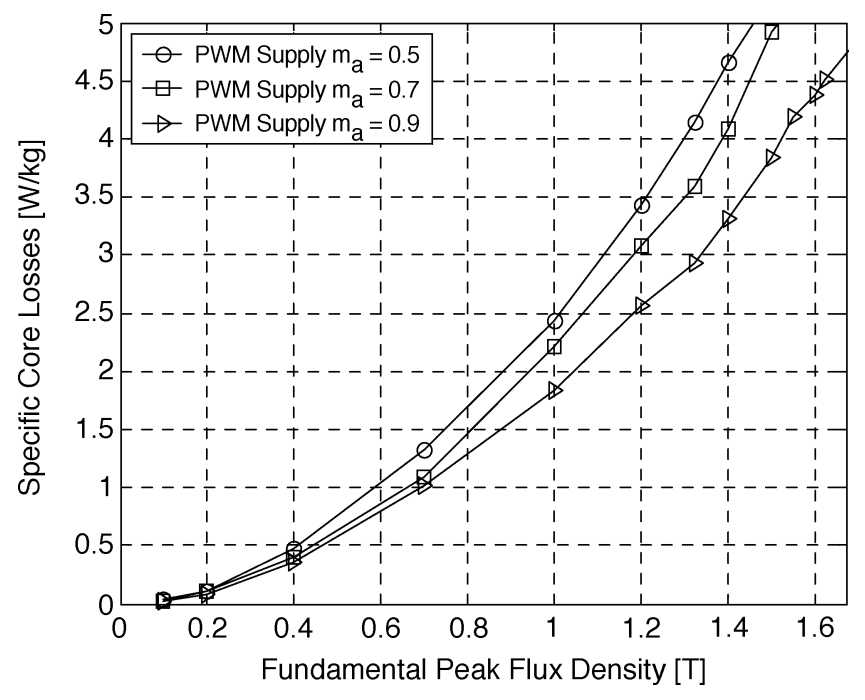

Fig. 2. Specific loss versus flux density for various modulation indices.

where $P_{h}, P_{e}$, and $P_{e x}$ are the hysteresis, eddy current, and excess loss components respectively, and $K_{i}(i=1,2,3)$ are constants determined from the physical properties of the steel. Reference [5] showed the origin of the excess loss component, $P_{e x}$. Each of the PWM inverter characteristics are considered below and their contribution to (1) is shown.

\section{B. Modulation Index}

With switching frequency fixed $\left(f_{s}=1 \mathrm{kHz}\right)$, core losses were measured for different $m_{a}$ values and plotted as a function of the fundamental peak flux as shown in Fig. 2.

Fig. 2 shows the measured specific losses as a function of the peak fundamental flux density. The results show that core losses decrease with increasing modulation index. In fact, if $m_{a} \geq 1$, the PWM output voltage tends to be the same as the full square wave inverter output; which have been found [4] to yield core losses less than those with PWM waveforms. The reduction of the modulation index causes an increase in the magnitudes of the harmonics; hence minor loops are likely to form, increasing the hysteresis losses. The major loss increase is heavily pronounced through the eddy current loss term. From (1), it is seen that for nonsinusoidal supplies, the eddy current loss component depend more on the rate of change of flux (slope, $\mathrm{dB} / \mathrm{dt}$ ), as observed by [6]. The current ripple has been found to increase with decreasing modulation index. Hence the loss increase under PWM supplies is attributed mainly to the increase in eddy current losses [4].

\section{Switching Frequency}

To investigate the dependence of core losses on the inverter switching frequency, the core loss was measured at different peak fundamental flux densities while keeping the fundamental output frequency at $50 \mathrm{~Hz}, m_{a}=0.9$ and varying $f_{s}$ from 500 $\mathrm{Hz}$ to $20 \mathrm{kHz}$. The specific core losses (in W/ $/ \mathrm{kg}$ ) are plotted as a function of switching frequency as shown in Fig. 3. The plots show that for $f_{s} \geq 5 \mathrm{kHz}$ the losses remain almost constant while $f_{s}$ is increased at constant flux density. Core losses are seen to increase slightly at low frequencies (less than 5 $\mathrm{kHz}$ ) — effectively what [4] observed. Increasing $f_{s}$ smooths out 


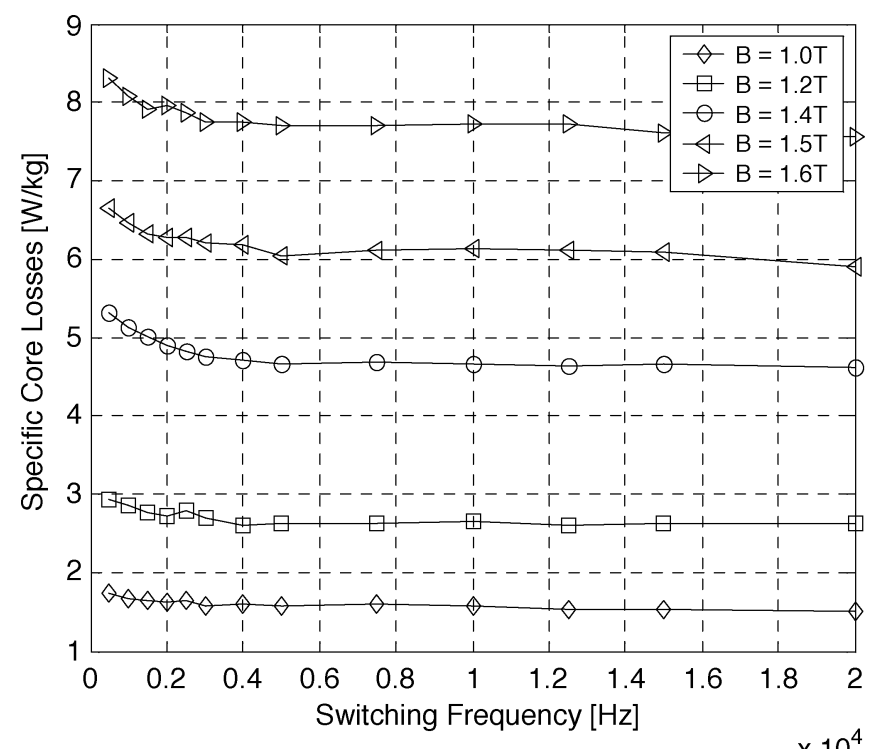

Fig. 3. Specific core losses versus flux density for different switching frequencies.

the flux steps $(\mathrm{dB} / \mathrm{dt})$ and current ripples, resulting in reduced core losses. In other words, since the PWM inverter harmonics appear as sidebands of the switching frequency and their multiples, increasing the switching frequency shifts the harmonics even farther away from the fundamental. However the drive switching losses will increase; hence it is not necessary to increase the switching frequency beyond $5 \mathrm{kHz}$. In other words the diminishing returns effect becomes effective, as drive losses will increase. In response to EPAct '92, American motor designers increased the mass of the steel used inside the motor to increase the area and reduce the operating induction levels, consequently reducing core losses. Fig. 3 shows why low induction levels would be desirable to reduce core losses, thus increasing motor efficiency.

\section{CORE LOSSES IN SRMS}

\section{A. Flux Model}

To measure the core losses in the SRM, the flux patterns in various segments of the machine should be known in order to derive the waveforms of the voltage source to be applied to the Epstein laminations core. A detailed mathematical development of the flux waveforms has been presented by [8] and [10]. Considering a 4 phase $8 / 6$ pole machine: suppose $U, V, W$ and $R$ represent the four phases of the machine with the associated flux linkages $\Phi_{U}(t), \Phi_{V}(t), \Phi_{W}(t)$ and $\Phi_{R}(t)$ as shown in Fig. 4.

In the SRM, each stator pole has one coil, and each phase consists of $m$ coils connected in series $(m=2,4,6 \ldots)$ and there is no mutual coupling among the different phases. The number of rotor poles $\left(N_{r}\right)$ determines the phase switching frequency

$$
\begin{aligned}
f_{p h} & =\frac{N_{r} \omega}{2 \pi} \\
T_{p h} & =\frac{1}{f_{p h}}
\end{aligned}
$$

where $\omega$ is the rotor mechanical speed (in rpm), $f_{p h}$ is the phase switching frequency and $T_{p h}$ is the switching period per phase.

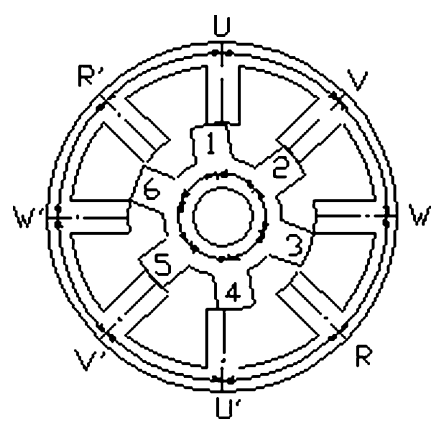

Fig. 4. Segments of a four-phase 8/6 SRM.

For a $q$-phase machine, the phases are excited successively with switching frequency

$$
f_{s}=q f_{p h} .
$$

The idealized stator flux pulse that is created through phase excitation is represented as a piecewise linear function

$$
\Phi(t)= \begin{cases}\frac{\Phi_{m}}{t_{r}} * t, & 0 \leq t \leq t_{r} \\ \frac{\Phi_{m}}{t_{f}-t_{r}} *\left(t_{f}-t\right), & t_{r} \leq t \leq t_{f} \\ 0, & t_{f} \leq t \leq T_{p h}\end{cases}
$$

where $\Phi_{m}$ is the peak flux in an SR motor, this peak flux is scaled by $1 / N_{p h}$, where $N_{p h}$ is the number of turns per phase, $t_{r}$ is the time it takes for the stator pole to move into full alignment with the rotor pole and $t_{f}$ is the time it takes (after full alignment) for the stator pole to come out of alignment with a rotor pole. Using these stator flux pulses, flux patterns in the other parts of the motor are derived. For the stator core segments, it is a direct summation of the stator pole fluxes, with appropriate signs and phases considered. Some stator yoke segments see bipolar flux patterns (segments WR, VW and UV); whereas some segments see nonreversing patterns (segment UR'), as shown in Fig. 9.

A rotor pole sees flux each time it approaches a stator pole (pulling into alignment). In one rotor revolution, the number of pulses each pole experiences in either direction equals the number of rotor poles. These pulses are delayed by a time shift of $T_{r}=2 \pi / \omega q m$ [8]. For the four phase, $(q=4, m=2)$, 8/6 SRM investigated, the rotor pole sees four positive pulses during half the revolution and four negative pulses during the other half of the revolution, as seen in Fig. 10. Half the rotor pole flux goes through the rotor core segment; hence rotor core segment flux patterns are derived by direct addition of the rotor pole flux patterns. The resulting stator and rotor flux patterns are shown in Figs. 5-11 for a speed of $600 \mathrm{rpm}(60 \mathrm{~Hz})$ with $t_{r}+t_{f}=T_{p h} / 2$ and $t_{r}=t_{f}$.

\section{B. Harmonic Analysis}

Clearly, the flux patterns that an SRM is subjected to differ from sinusoidal waveforms. The frequency content of the different fluxes inside the motor is investigated and analytic expressions for the Fourier coefficients are derived. These coefficients are used to predict core losses by applying superposition. The predicted results are compared with the total core loss measured with the actual flux waveforms. To derive the Fourier coefficients, each flux waveform can be defined analytically by 


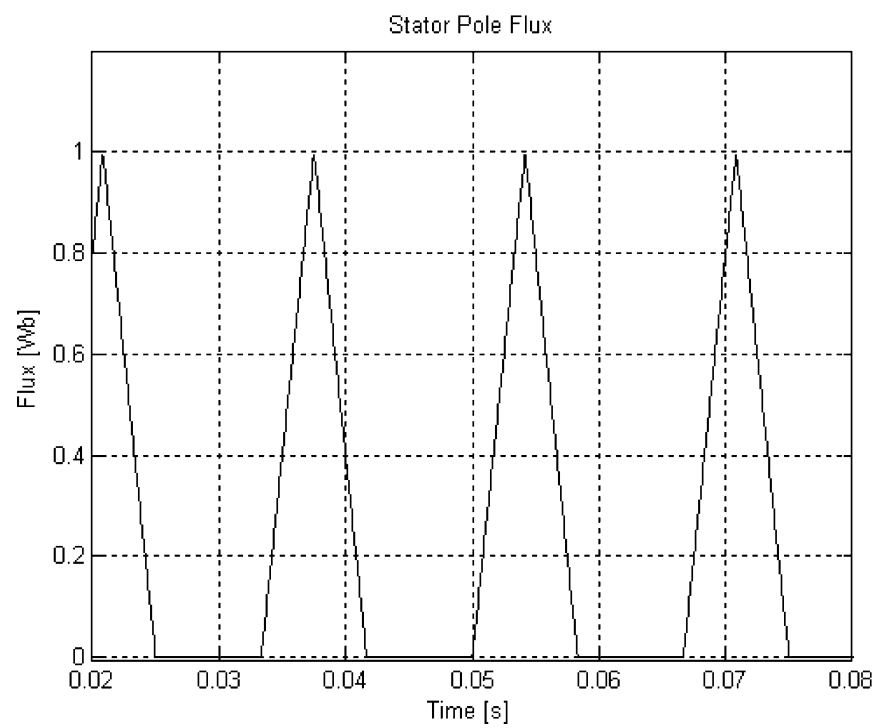

Fig. 5. Typical SRM stator pole flux waveforms from simulations.

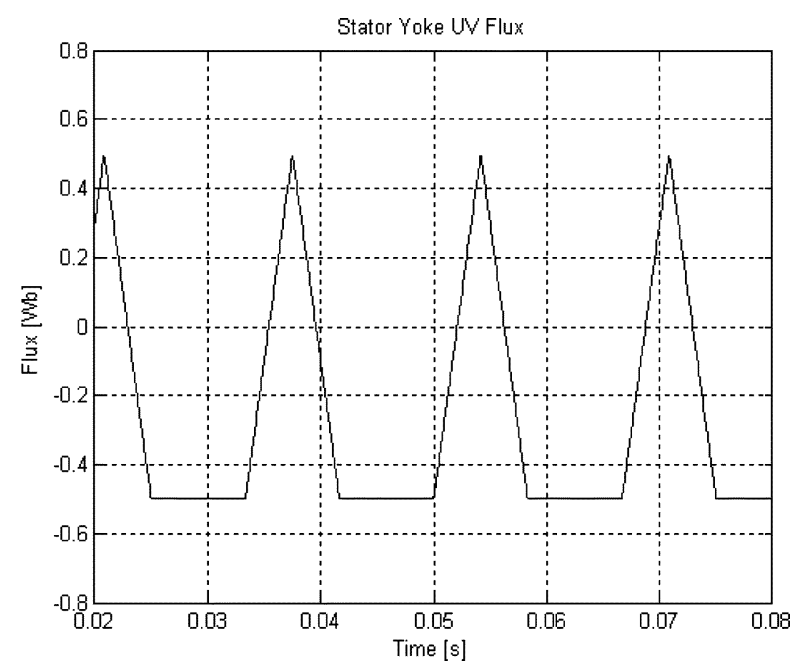

Fig. 6. Stator yoke UV flux waveforms from simulations.

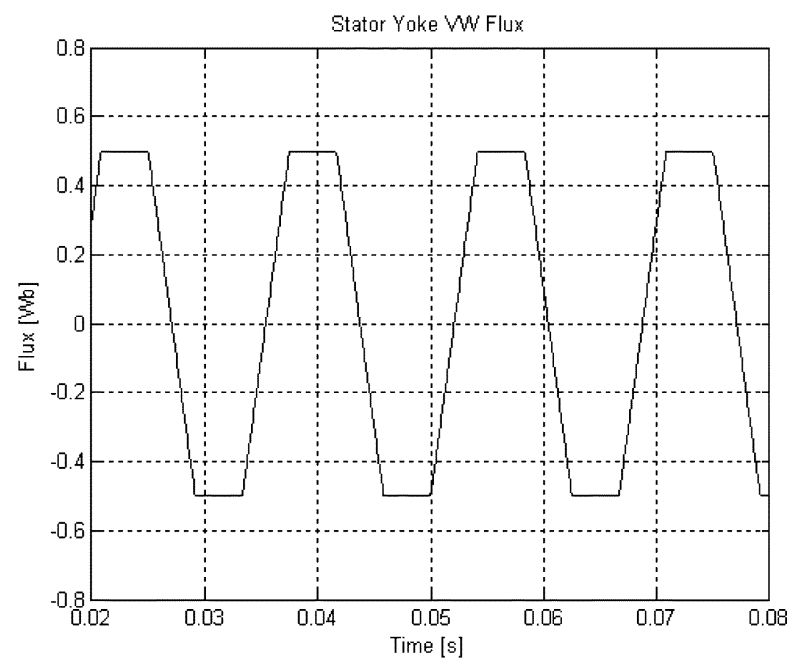

Fig. 7. Stator yoke VW flux waveforms from simulations.

piecewise continuous functions and integration applied over the appropriate time intervals. A second method is to use the Fourier transform of the stator pole flux (as a base or reference signal),

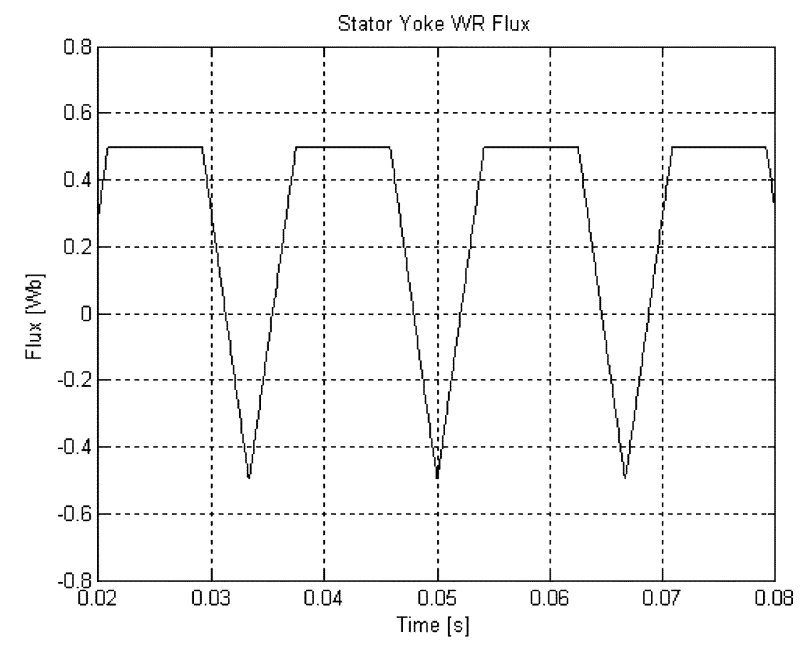

Fig. 8. Stator yoke WR flux waveforms from simulations.

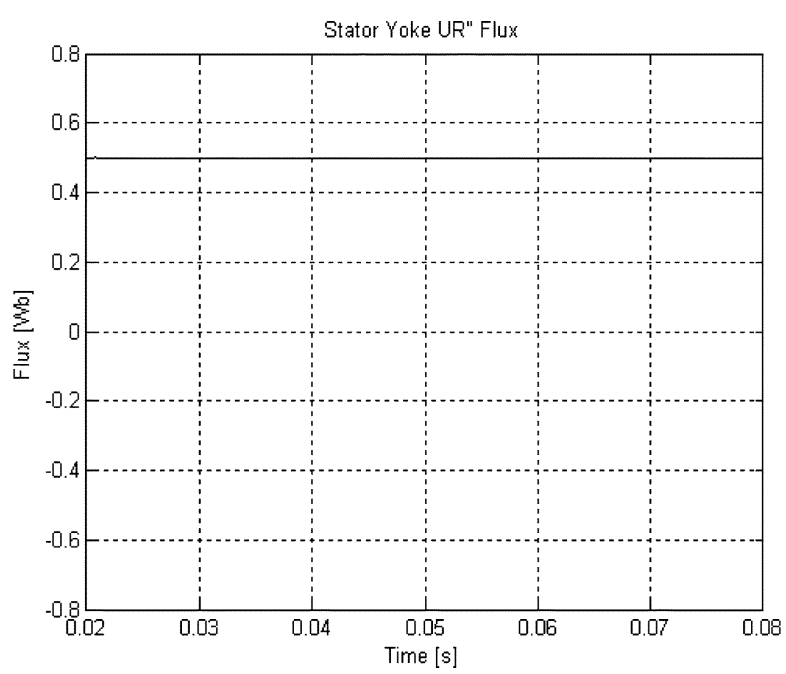

Fig. 9. Stator yoke UR' flux waveforms from simulations.

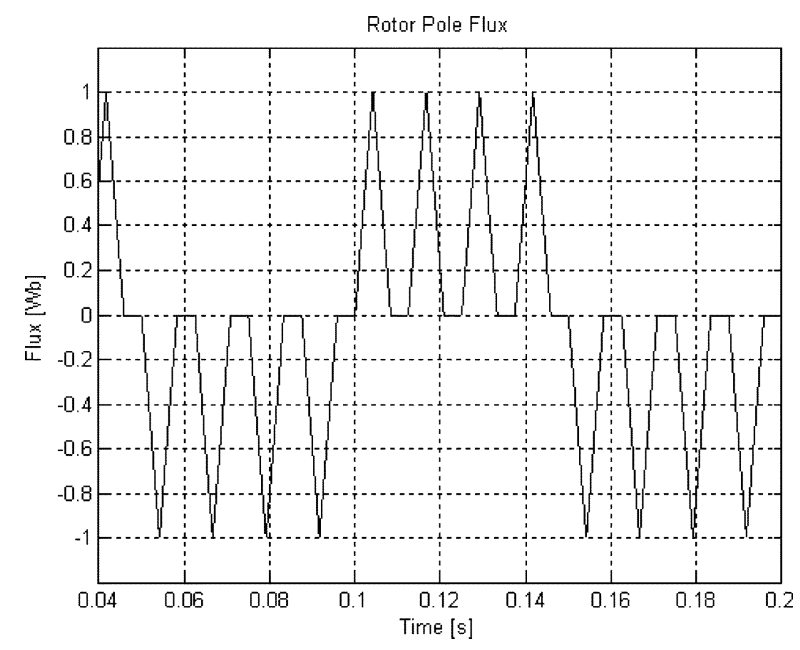

Fig. 10. Typical SRM rotor pole flux waveforms from simulations.

which is a triangle, with a known Fourier transform. From this, and applying the proper delays for the respective parts inside the motor, the coefficients for the different parts of the motor can be calculated. 


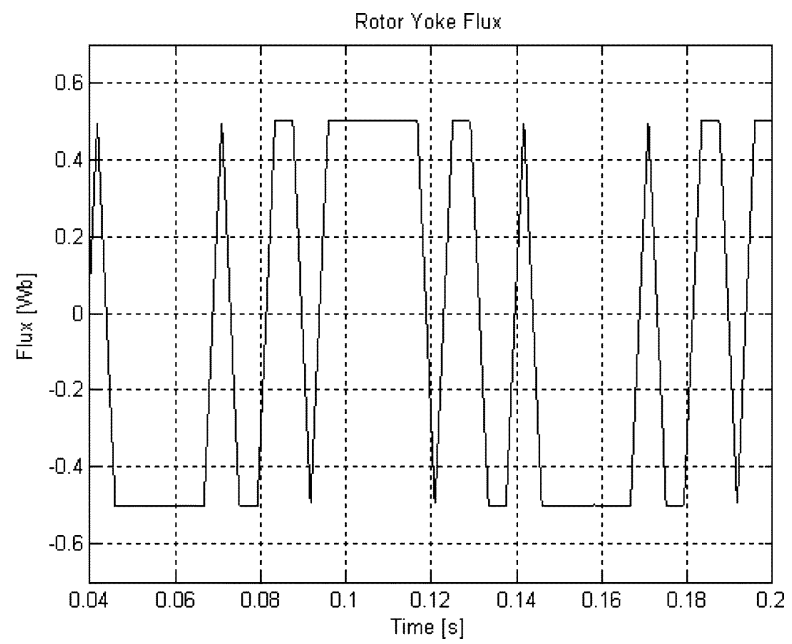

Fig. 11. Typical SRM rotor yoke flux waveforms from simulations.

The general Fourier coefficients for any realizable waveform $x(t)$ are given by

$$
x(t)=\frac{a_{0}}{2}+\sum_{h=1}^{\infty}\left\{a_{h} \cos (h \omega t)+b_{h} \sin (h \omega t)\right\} .
$$

If $X(w)$ is the Fourier transform of $x(t)$, then

$$
C_{h}=\left.\frac{X(\omega)}{T}\right|_{\omega \rightarrow h w_{o}}
$$

with $a_{h}$ and $b_{h}$ defined as follows:

$$
\begin{aligned}
a_{h} & =2 \operatorname{Re}\left\{C_{h}\right\} \\
b_{h} & =-2 \operatorname{Im}\left\{C_{h}\right\}
\end{aligned}
$$

where $a_{0}$ is the average value of $x(t), h$ is the harmonic order, and $\omega_{0}=2 \pi / T$ and $T$ are the (fundamental) period of the waveform under consideration.

1) Stator Pole and Yoke Flux Patterns: Equation (9) is greatly simplified by exploiting the symmetry properties of the Fourier series. From Fig. 5, it is observed that the stator pole flux pattern is an even function. Therefore there is a nonzero average and only the real parts of $C_{h}$ exist, with all $b_{h}$ terms zero. The simplified expressions for the coefficients are as shown by (13), with $T=T_{p h}$ and $\omega=2 \pi / T_{p h}$

$$
a_{h}=\frac{2 \Phi_{m}}{(h \omega)^{2} t_{r} T}\left(1-\cos \left(h \omega t_{r}\right)\right) .
$$

Thus, the stator pole flux patterns in segment $U$ are given by the analytical expression

$$
\Phi_{u}(t)=\frac{a_{0}}{2}+a_{h} \cos (h \omega t) .
$$

The other pole fluxes are derived by phase shifting $\Phi_{\mathrm{u}}(\mathrm{t})$ by $T_{w}$ accordingly, as shown in (15)-(17)

$$
\begin{aligned}
\Phi_{V}(t) & =\frac{a_{0}}{2}+a_{h} \cos \left(h \omega\left(t-T_{w}\right)\right) \\
\Phi_{W}(t) & =\frac{a_{0}}{2}+a_{h} \cos \left(h \omega\left(t-2 T_{w}\right)\right) \\
\Phi_{R}(t) & =\frac{a_{0}}{2}+a_{h} \cos \left(h \omega\left(t-3 T_{w}\right)\right)
\end{aligned}
$$

\begin{tabular}{|c|c|c|}
\hline \multirow{2}{*}{$\begin{array}{l}\text { Harmonic Order } \\
\text { (h) -- Multiples of } \\
60 \mathrm{~Hz}\end{array}$} & & $\frac{\hat{B}_{h}}{\hat{B}_{1}}$ \\
\hline & Stator Pole & Stator Core VW \\
\hline 1 & 1.000 & 1.461 \\
\hline 2 & 0.494 & -- \\
\hline 3 & 0.111 & 0.131 \\
\hline 5 & 0.039 & 0.055 \\
\hline 6 & 0.054 & -- \\
\hline 7 & 0.017 & 0.029 \\
\hline
\end{tabular}

TABLE I

Flux Harmonics in STATOR POLE AND Yoke SEgments

where the average term is

$$
a_{0}=\frac{2 \Phi_{m} t_{r}}{T_{p h}}
$$

with $T_{\omega}=T_{p h} / q$-a time delay between the stator pole strokes. The stator core fluxes are derived by addition of the above stator flux patterns, with the respective signs observed.

The resulting Fourier components for the stator section are tabulated in Table I as ratios of peak harmonics to the fundamental peak stator flux density. This is for the stator pole and stator core VW segment with the stator peak flux set to unity.

From Table I it is observed that the stator pole flux patterns have up to three dominant frequencies (the 1st, 2nd, and 3rd harmonics) [8]. This is a unique feature for all 4-phase 8/6 SRMs. It was observed that the fundamental peak stator flux was less than $50 \%$ of the peak stator flux (unity), This observation was also made by [8]. The stator pole and yoke flux density harmonics diminish with increasing harmonic orders. Stator core VW segment sees only odd harmonics with a fundamental component $46 \%$ higher than the stator pole fundamental. The other core segments, UV and WR have a similar harmonic spectrum as the stator pole. The stator core segment UR' has significantly lower harmonics, resulting in lower core losses in this section of the motor [9]. Hence, for the stator section, only the stator pole and yoke segment VW were investigated.

2) Rotor Pole and Yoke Flux Patterns: The rotor pole flux waveforms are odd functions, thus simplifying the mathematics, since $a_{h}$ and $b_{h}$ terms (from (9)) are zeros for even harmonics, with a zero average value. The fundamental frequency of the rotor pole flux is less than the stator pole flux fundamental frequency $\left(f_{1 \text { rotor }}=f_{p h} / N_{r}\right)$, and with the corresponding period, $T_{\text {rot }}=1 / f_{1 \text { rotor }}$. Starting with the stator pole flux Fourier transform and applying proper phase shifts and appropriate signs, the rotor pole flux Fourier coefficients are obtained by adding the resulting eight (in general $2 q$ ) coefficients. The expressions for the rotor flux coefficients are included in the appendices. Applying (9)-(12), with the period derived from the rotor pole frequency, the rotor pole and yoke flux Fourier coefficients are extracted and shown in Table II.

From Table II, for the rotor and yoke segment fluxes, it is observed that the fundamental peak fluxes are $7 \%$ higher than the stator pole fundamental peak. The flux waveforms of the rotor pole and core have a fundamental frequency of $f_{p h} / N_{r}=$ $10 \mathrm{~Hz}$ and a carrier frequency of $\left(N_{s} / N_{r}\right) f_{p h}=80 \mathrm{~Hz}$. It 
TABLE II

Flux HaRmonics Rotor POLE AND YOKE SEGMENT

\begin{tabular}{ccc}
\hline \multirow{2}{*}{$\begin{array}{c}\text { Harmonic Order } \\
\text { (h) -- Multiples of } \\
10 \mathrm{~Hz}\end{array}$} & \multicolumn{2}{|}{$\left|\frac{\hat{B}_{h}}{\hat{B}_{1}}\right|$} \\
\cline { 2 - 3 } & Rotor Pole & Rotor Core \\
\hline 1 & 1.068 & 1.068 \\
\hline 3 & 0.422 & 0.212 \\
\hline 5 & 0.385 & 0.385 \\
\hline 7 & 0.804 & 0.804 \\
\hline 9 & 0.661 & 0.331 \\
\hline 11 & 0.212 & 0.211 \\
\hline 13 & 0.151 & 0.151 \\
\hline 15 & 0.237 & 0.118 \\
\hline 17 & 0.136 & 0.136 \\
\hline 19 & 0.027 & 0.027 \\
\hline
\end{tabular}

is also observed that the sidebands of the rotor pole flux density carrier frequency, the 7th and 9th harmonics contain significant amounts of the stator fundamental peak flux. These harmonics are at frequencies close to the stator flux fundamental frequency; hence a reasonable comparison can only be made around these two components. For the nonmultiples of three harmonics, the rotor pole and yoke harmonics have similar ratios to the stator fundamental peak, whereas, for multiples of the $3 \mathrm{rd}$ harmonic, the rotor yoke sees half the corresponding rotor pole flux harmonic.

\section{Predicted Versus Measured Core Loss}

The aim is to investigate the use of the Fourier series by applying superposition to estimate core losses using the core loss data from a steel manufacturer and a given flux harmonic spectrum. Using the flux waveforms from Figs. 5-11, excitation voltages were derived and used to excite the Epstein frame with 0.0140 in. $(0.36 \mathrm{~mm})$ commercial electrical steel. The fundamental stator peak flux was used as reference.

The original loss data from steel manufacturers did not include all harmonic frequencies under consideration. To estimate core loss at those frequencies not given by the steel manufacturer, the following steps were used: Firstly, total core loss against frequency at the given peak flux densities is plotted (this is done for all the given flux densities) and a polynomial fit obtained. Secondly, using these polynomials and substituting a harmonic frequency of interest, the total core loss at that particular frequency is calculated. The total core loss is plotted against peak flux densities (generally, power curves) at that frequency of interest, and curve fitted. Harmonic flux densities can be substituted and harmonic core loss data obtained. In this way the total core loss under harmonic frequencies and flux densities is calculable.

For the nonfundamental frequency core loss, the low flux density results (typically, $<0.7 \mathrm{~T}$ ) are used to get more accurate results. This is because the harmonic flux magnitudes are less than $0.7 \mathrm{~T}$ and using the higher flux density data leads to higher error. However, since the fundamental component is used as a reference, to predict core losses under this frequency requires the use of the whole flux density range. This method is applied to predict core loss when exposed to SRM equivalent waveforms for each part.

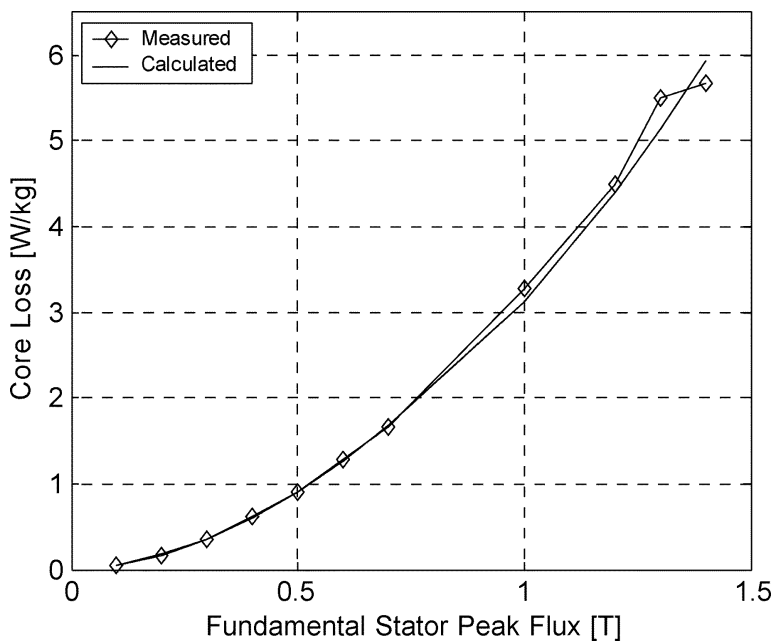

Fig. 12. Stator pole measured versus predicted results.

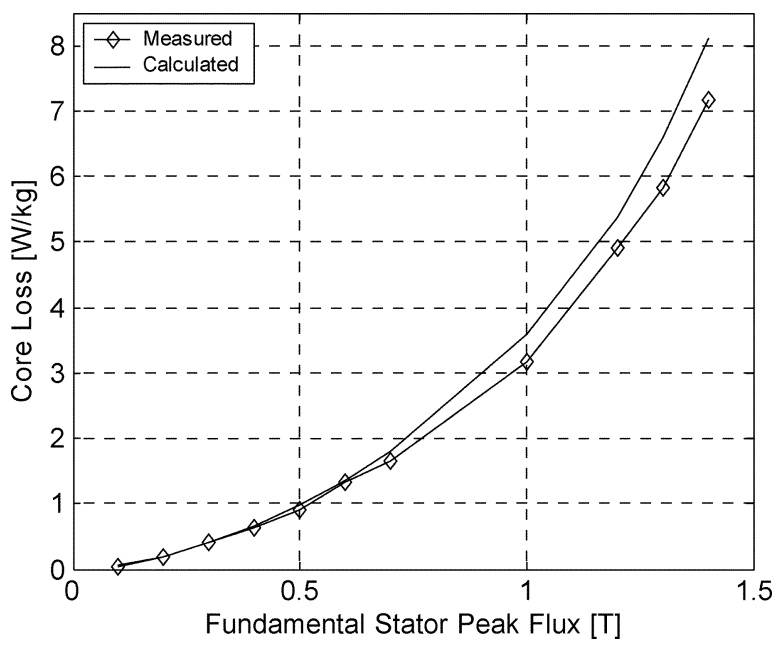

Fig. 13. Stator yoke segment VW measured versus predicted results.

TABLE III

COMPARISON OF PREDICTED AND MEASUREd RESUlTS

\begin{tabular}{|c|c|c|c|c|c|c|}
\hline \multirow{2}{*}{$\begin{array}{c}\text { Fund. } \\
\text { Stator } \\
\text { Peak B } \\
{[\mathrm{T}]}\end{array}$} & \multicolumn{3}{|c|}{ Stator Pole } & \multicolumn{3}{|c|}{ Core VW } \\
\hline & $\begin{array}{c}\text { Cal. } \\
{[\mathrm{W} / \mathrm{kg}]}\end{array}$ & $\begin{array}{l}\text { Meas. } \\
{[\mathrm{W} / \mathrm{kg}]}\end{array}$ & $\%$ Diff. & $\begin{array}{l}\text { Calc. } \\
{[\mathrm{W} / \mathrm{kg}]}\end{array}$ & $\begin{array}{l}\text { Meas. } \\
{[\mathrm{W} / \mathrm{kg}]}\end{array}$ & $\%$ Diff \\
\hline 0.7 & 1.685 & & 1.25 & & 1.659 & 7.54 \\
\hline 1.0 & 3.128 & 3.279 & 4.82 & 3.586 & 3.181 & 11.28 \\
\hline 1.2 & 4.404 & 4.495 & 2.06 & 5.393 & 4.918 & 8.81 \\
\hline 1.4 & 5.945 & 5.628 & 5.34 & 8.109 & 7.170 & 11.58 \\
\hline
\end{tabular}

\section{A. Stator Loss Comparison}

Figs. 12 and 13 show a comparison of the predicted and measured core loss results with the Epstein frame excited by the equivalent flux density waveforms for the stator pole and yoke segments.

Figs. 12 and 13 show good agreement between the predicted and measured results. These results are tabulated in Table III. The $\%$ difference is the ratio of the absolute difference between the predicted and measured results to the calculated results.

Core losses in the stator pole are predicted with an error of less than $4 \%$ on average. The predicted results for the stator 


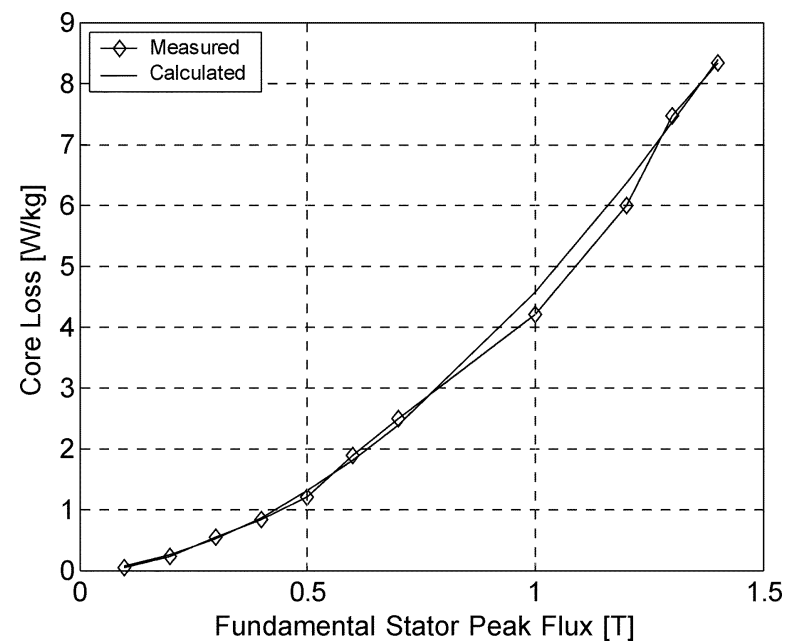

Fig. 14. Rotor pole results measured versus predicted results.

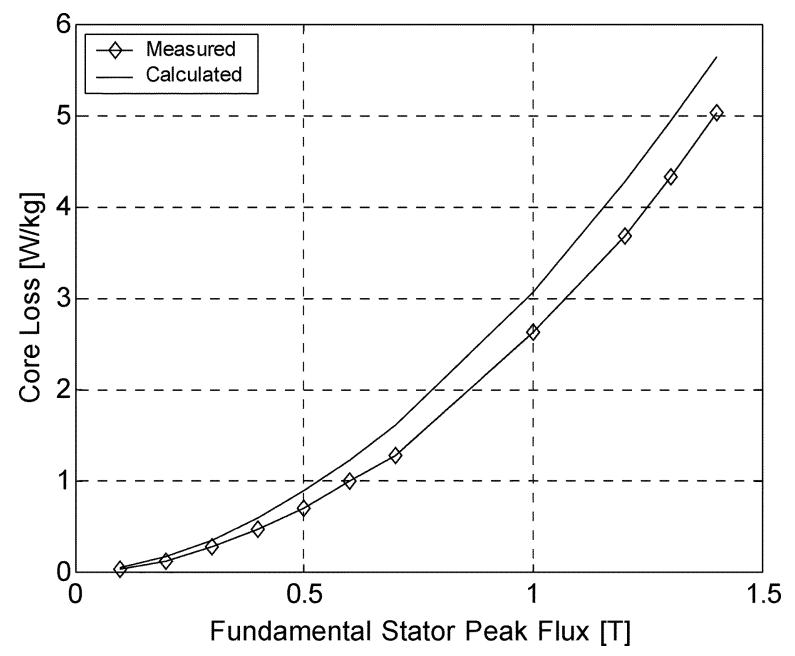

Fig. 15. Rotor yoke results measured versus predicted results.

yoke section VW are within 10\% (on average) of the measured results.

\section{B. Rotor Loss Comparison}

Figs. 14 and 15 show loss results measured using the equivalent flux density waveforms for the rotor pole and yoke segments with results tabulated in Table IV.

With the rotor pole core losses, the predicted and measured results agree within a 5\% range. The rotor core results show a relatively larger error between the predicted and measured results, with an average of $15 \%$ difference. This relatively larger error is due to the partial saturation of the laminations for this part of the motor.

\section{SRM Loss Trend}

Fig. 16 shows the measured loss trend inside the SRM as a function of the fundamental peak stator flux density. Also shown in Fig. 16 is the $60 \mathrm{~Hz}$ sinusoidal core loss plot to emphasize the core loss increase.

The rotor poles are seen to experience the highest losses. The loss variations in the motor can be attributed to three factors: 1 )
TABLE IV

COMPARISON OF PREDICTED AND MEASURED RESULTS

\begin{tabular}{|c|c|c|c|c|c|c|}
\hline \multicolumn{7}{|c|}{ Rotor, $10 \mathrm{~Hz}$ fundamental } \\
\hline \multirow{2}{*}{$\begin{array}{c}\text { Fund. } \\
\text { Stator } \\
\text { Peak Flux } \\
{[\mathrm{T}]} \\
\end{array}$} & \multicolumn{3}{|c|}{ Rotor pole } & \multicolumn{3}{|c|}{ Rotor core } \\
\hline & $\begin{array}{l}\text { Calc. } \\
{[\mathrm{W} / \mathrm{kg}]}\end{array}$ & $\begin{array}{l}\text { Meas. } \\
{[\mathrm{W} / \mathrm{kg}]}\end{array}$ & $\begin{array}{c}\% \\
\text { Diff. }\end{array}$ & $\begin{array}{l}\text { Calc. } \\
{[\mathrm{W} / \mathrm{kg}]}\end{array}$ & $\begin{array}{l}\text { Meas. } \\
\mid[\mathrm{W} / \mathrm{kg}]\end{array}$ & $\begin{array}{c}\% \\
\text { Diff. }\end{array}$ \\
\hline 0.7 & 2.38 & 2.50 & 4.86 & 1.61 & 1.28 & 20.37 \\
\hline 1.0 & 4.56 & 4.20 & 7.82 & 3.07 & 2.62 & 14.72 \\
\hline 1.2 & 6.35 & 6.00 & 5.52 & 4.27 & 3.67 & 14.04 \\
\hline 1.4 & 8.41 & 8.32 & 1.06 & 5.64 & 5.02 & 11.12 \\
\hline
\end{tabular}

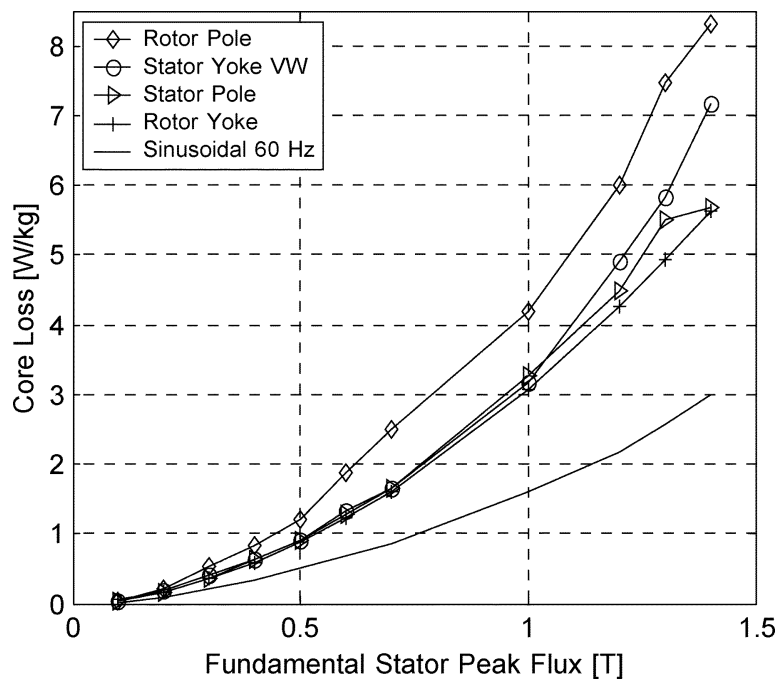

Fig. 16. Core loss variation inside the SRM.

different flux peaks reached, 2) rate of change of flux $(\mathrm{dB} / \mathrm{dt})$ and 3 ) the different flux frequencies. The first affects mostly the hysteresis losses, known to depend on the peak flux reached. In a typical SRM, the rotor pole reaches the same maximum flux as the stator poles. The second factor, $\mathrm{dB} / \mathrm{dt}$, affects mainly the eddy current losses; which are dependent on the rate of change of flux [6]. From Fig. 10, for one rotor revolution the rotor pole flux slope changes signs sixteen times, whereas the stator poles flux changes signs twelve times. The third factor, frequency dependence, has been widely published: linear for hysteresis losses and quadratic for eddy current losses. The strong side bands of the carrier component in the rotor pole flux density are at frequencies higher than the fundamental frequency of the stator pole flux; hence rotor poles incur higher losses. Reference [8] reported similar results as reported in this paper, for a 6/4 SRM, however, reference [10] reported different results for a $12 / 10$ machine.

In Table I, it was shown that the fundamental flux density in yoke segment VW is $46 \%$ higher than the stator pole fundamental, implying higher core losses. Although the yoke segment VW does not have even harmonics, as in the stator pole, the strong odd harmonics present increased losses considerably.

\section{CONCLUSIONS}

This paper has successfully applied the test bench and methodologies proposed by [4] and by measurements verified 
the effects of varying the modulation index and the switching frequency on PWM core losses. The paper confirms that PWM core losses are highly dependent on the modulation index, and for high switching frequency $(\geq 5 \mathrm{kHz})$ core losses are relatively independent to changes in the switching frequency. It is hoped that the standardization bodies (e.g., IEC, ASTM, etc.) will look into developing standards for nonsinusoidal core loss measurements, especially for PWM waveforms).

The paper has also shown the loss trend inside the SRM theoretically, and verified through measurements. The rotor pole was found to incur higher core losses. The sidebands of the carrier frequency in the rotor pole flux density were found to be the main loss-contributing harmonics. The loss trend in SR machines presented in this paper gives motor designers a feel of the loss distribution inside the machine and thus presents opportunities for design optimization.

The errors involved in using the Fourier series to predict core losses have been presented. The stator pole losses were predicted with $4 \%$ error, and yoke segment $\mathrm{VW}$ was predicted with $10 \%$ error. The rotor pole losses were predicted within a 5\% range (on average), and the rotor yoke losses were predicted within a $15 \%$ range (on average). These results show a good starting point for lamination core loss predictions without using finite element packages.

For custom made steel, steel producers could also use the knowledge of how electrical steel behaves under nonsinusoidal supplies to manipulate their steel chemical composition to minimize core loss. For a practical machine, factors such as fringing effects, saturation, and rotational losses must be taken into account for accurate core loss prediction. For future work, core losses in SRM electrical steel cut to a particular design will be measured and compared with the Epstein frame results.

\section{APPENDIX}

Rotor pole flux Fourier coefficients' expansion:

Let $x=\omega t_{r} / 2 \pi$, then the Fourier transform of rotor pole flux

$$
\begin{array}{r}
X(\omega)=\Phi_{m} t_{r}\left(\frac{\sin (x)}{x}\right)^{2}\left[1+e^{\left(-j \omega 3 t_{r}\right)}+e^{\left(-j \omega 6 t_{r}\right)}+e^{\left(-j \omega 9 t_{r}\right)}\right. \\
\left.-e^{\left(-j \omega 12 t_{r}\right)}-e^{\left(-j \omega 15 t_{r}\right)}-e^{\left(-j \omega 18 t_{r}\right)}-e^{\left(-j \omega 21 t_{r}\right)}\right]
\end{array}
$$

where $\omega$ is the rotor radian frequency $\omega_{\text {rot }}=2 \pi f_{p h} / N_{r}$.

\section{REFERENCES}

[1] N. Mohan, T. M. Undeland, and W. P. Robbins, Power Electronics: Converters, Applications and Design, 2nd ed. New York: Wiley, 1991.

[2] L. T. Mthombeni, P. Pillay, and A. S. Naidu, "Lamination core loss measurements in machines operating with PWM or nonsinusoidal excitation," in Proc. IEEE Int. Electric Machines Drives Conf., vol. 2, Madison, WI, Jun. 1-4, 2003.

[3] EMERF (Electric Motor Education and Research Foundation), Lamination Steels Second Edition: A Compandium of Lamination Steel Alloys Commonly Used in Electrical Motors, CD-ROM Compilation, 2002.

[4] A. Boglietti, P. Ferraris, M. Lazzari, and M. Pastorelli, "About the possibility of defining a standard method for iron loss measurements in soft magnetic materials with inverter supply," IEEE Trans. Ind. Appll. Soc., vol. 33, no. 5, pp. 1283-1288, Sep./Oct. 1997.

[5] G. Bertotti, "Physical interpretation of eddy currents losses in ferromagnetic materials," J. Appl. Phys., vol. 57, no. 6, pp. 2118-2126, Mar. 1985.
[6] M. S. Lancarotte, A. d. A. Penteado Jr., and São Paulo, "Prediction of magnetic losses under sinusoidal or nonsinusoidal induction by analysis of magnetization rate," IEEE Trans. Energy Convers., vol. 16, no. 2, pp. 174-179, Jun. 2001.

[7] M. Amar and R. Kaczmarek, "A general formula for prediction of iron losses under nonsinusoidal voltage waveform," IEEE Trans. Magn., vol. 31, no. 5, pp. 2504-2509, Sep. 1995.

[8] P. Materu and R. Krishnan, "Estimation of switched reluctnace motor losses," in Proc. Conf. Rec. IEEE Ind. Appl. Soc. Annu. Meeting, vol. 1, Oct. 2-7, 1988, pp. 79-90.

[9] T. J. E. Miller, Switched Reluctance Motors and Their Control. London, U.K.: Oxford Univ. Press, 1993

[10] J. Faiz and M. B. B. Sharafin, "Core losses estimation in a multiple teeth per stator pole switched reluctance motor," IEEE Trans. Magn., vol. 30, no. 2, pp. 189-195, Mar. 1994.

[11] L. T. Mthombeni and P. Pillay, "Core losses in motor laminations exposed to high frequency or nonsinusoidal excitation," in Proc. 38th Ind. Appl. Soc. Аnnu. Meeting, vol. 2, Oct. 12-16, 2003, pp. 1090-1097.

[12] A. Boglietti, P. Ferraris, M. Lazzari, and M. Pastorelli, "Change of the iron losses with the switching supply frequency in soft magnetic materials supplied by PWM inverter," IEEE Trans. Magn., vol. 31, no. 6, pp. 4250-4252, Nov. 1995.

[13] Y. Chen and P. Pillay, "An improved formula for lamination core loss calculations in machines operating with high frequency and high flux density excitation," in Proc. 37th Ind. Appl. Soc. Annual Conf., vol. 2, Oct. 13-18, 2002, pp. 759-766.

[14] A. Boglietti, P. Ferraris, M. Lazzari, and M. Pastorelli, "Effects of different modulation index on the iron losses in soft magnetic materials supplied by PWM inverter," IEEE Trans. Magn., vol. 29, no. 6, pp. 3234-3236, Nov. 1993.

[15] G. R. Slemon and X. Liu, "Core loss in permanent magnet motors," IEEE Trans. Magn., vol. 26, no. 5, pp. 1653-1655, Sep. 1990.

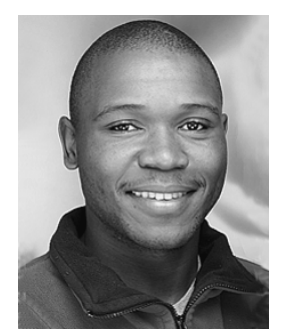

Tsakani Lotten Mthombeni (S'03) received the B.S. degree from the University of Cape Town, Cape Town, South Africa, in 2001 and the M.S. degree in 2003 from Clarkson University, Potsdam, NY, where he is currently pursuing the Ph.D. degree in electrical engineering.

His research interests include machines and drives, energy management, motor core losses, and motor efficiency.

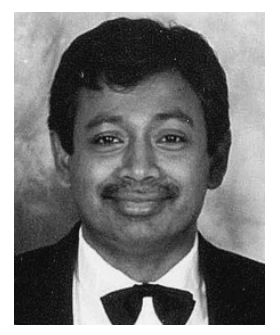

Pragasen Pillay (S'84-M'87-SM'92-F'05) received the B.S. degree from the University of Durban-Westville, Durban, South Africa, in 1981, the M.S. degree from the University of Natal, South Africa, in 1983, and the Ph.D degree from the Virginia Polytechnic Institute and State University, Blacksburg, in 1987, while supported by a Fulbright Scholarship.

Currently, he is a Professor in the Department of Electrical and Computer Engineering, Clarkson University, Potsdam, NY, where he holds the Jean Newell Distinguished Professorship in Engineering. From 1988 to 1990, he was with the University of Newcastle-upon-Tyne, Newcastle-upon-Tyne, U.K. From 1990 to 1995, he was with the University of New Orleans, New Orleans, LA. He has been an Adjunct Professor at the University of Cape Town, Cape Town, South Africa, since 1999.

Dr. Pillay is a member of the Power Engineering, Industry Applications, Industrial Electronics, and Power Electronics Societies. He is also a member of the Electric Machines Committee, Past Chairman of the Industrial Drives Committee within the Industry Applications Society, and Past Chairman of the Induction Machinery Subcommittee in the Power Engineering Society. He is a Fellow of the IEE, U.K., and a Chartered Electrical Engineer. He is also a member of the Academy of Science of South Africa and has organized and taught short courses in electric drives at the Annual Meeting of the Industry Applications Society. His research and teaching interests are in modeling, design, and control of electric motors and drives for industrial and alternate energy applications 